REVISTA CHILENA DE LITERATURA

Noviembre 2008, Número 73, 163 - 188

\title{
EL CRONOTOPO DE LA EXCLUSIÓN EN TRES NOVELAS DE LA GENERACIÓN DEL 38
}

\author{
Cristián Montes \\ Universidad de Chile \\ cmontes@vtr.net
}

RESUMEN / ABSTRACT

Se propone aquí la existencia, en tres novelas de la generación del 38, de un cronotopo de exclusión que caracteriza la representación de la ciudad. Dicho cronotopo tensiona y fracciona el propósito de integración social del discurso nacionalista.

PALABRAS CLAVE: generación, exclusión, cronotopo, novela, ciudad

This article analyzes three novels of the Generation of the year 1938 and proposes the existence of a chronotope of exclusion that characterizes the representation of the city. This chronotope places stress upon and finally destroys the social integration attempted by the nationalist discourse.

KEY WORDS: Generation, exclusion, chronotopos, novel, town.

Se intentará a continuación dar cuenta de las diversas modalidades en que se despliega el cronotopo de la exclusión en tres novelas de la generación del 38: Angurrientos (1940)1, de Juan Godoy, La sangre y la esperanza

1 Se trabajará aquí con la segunda edición asumida por LOM Ediciones, Santiago, 1996 (Primera edición: 1940). 
$(1943)^{2}$, de Nicomedes Guzmán y El tiempo banal (1955), de Guillermo Atías. Respecto a esta última novela es necesario señalar que, pese su fecha de publicación, la crítica especializada la ubica dentro de la generación del 38 y no de la generación del $50^{3}$. Si bien es cierto, por la edad del autor y el momento de aparición de la novela, Atías está más cerca de esta segunda generación, las preocupaciones centrales de su novelística lo insertan en la generación anterior. En este sentido, frente a los narradores del 50, a quienes "les molesta la exaltación de lo nacional que hay en la generación precedente, porque ellos se están internacionalizando a toda máquina" (Luis Sánchez Latorre 375), Atías, en cambio, refuerza el vínculo de la literatura con la realidad nacional:

\begin{abstract}
"Una novela no se puede inventar como un acto de fantasía; no podemos incrustar en nuestros libros situaciones que no nos son dadas por nuestra realidad o nuestra propia irracionalidad, aunque esto nos desespere como libres creadores (...) Es evidente que hay una relación obvia entre el proceso de creación artística y el medio social" (Atías "La Literatura" 159-160).
\end{abstract}

Cabe decir, sin embargo, que a pesar de coincidir con la crítica especializada respecto a la pertenencia de Atías a la generación del 38, es necesario reconocer que su escritura presenta diferencias evidentes con la de Juan Godoy y Nicomedes Guzmán. En este sentido, la retórica un tanto sobrecargada de barroquismo, un naturalismo todavía regulador de la perspectiva narrativa, la denuncia social marcadamente explícita y el énfasis documental que caracterizan a la narrativa del 38, dan paso, en la novela de Atías, a una escritura de mayor complejidad y riqueza expresiva. En este último se trata de una producción artística donde la dimensión psicológica de los personajes es ampliamente desplegada, una propuesta creativa en la que el carácter de la denuncia social es más implícito y sutil, una conciencia sobre la autonomía del objeto artístico que se evidencia en la complejidad

2 Se ocupará en este caso la edición realizada por Ediciones Olimpo, Santiago, 2003 (Primera Edición: 1943).

3 Tanto Promis en La novela chilena del último siglo (1993), como Fernando Alegría en Las fronteras del realismo. Literatura chilena del siglo XX (1962) y Miguel Serrano en Antología del verdadero cuento en Chile (1938), ubican a Atías como exponente representativo de la generación del 38. 
formal, y una representación donde se elaboran "situaciones de conciencia y comportamientos humanos de carácter existencial” (Sarrochi 379).

Aclarado lo anterior y tomando en cuenta las propuestas de José Promis, tanto Angurrientos como La sangre y la esperanza y El tiempo banal se insertan en un programa narrativo que Promis define como novela del acoso. Se refiera con dicha nominación a una narrativa que visualiza al ser humano en tensión y disputa con diversas formas de opresión, ya sea política, social, psicológica o existencial. Al interior de la novela del acoso existen, a la vez, dos tendencias opuestas: una que evade el compromiso ideológico, en pos de una creación subjetiva donde predomina una representación estética de la conciencia (por ejemplo, la narrativa de María Luisa Bombal) y una vertiente social que ve en la literatura una vía de transformación de la realidad. Esta segunda tendencia posee una perspectiva social materialista en su interpretación histórica y propone que la literatura debe estar al servicio de la lucha popular (115-118). Cabe destacar que las novelas que en este trabajo se analizarán pertenecen a esta segunda corriente, la que agrupa a autores tales como Volodia Teitelboim, Juan Godoy, Nicomedes Guzmán, Guillermo Atías, Reinaldo Lomboy, Andrés Sabella, Carlos Droguet y Fernando Alegría, entre otros.

\section{CRONOTOPÍA Y CONFIGURACIÓN DE MUNDO}

El concepto de cronotopo - unidad temporo espacial que determina la unidad artística de la obra literaria en su actitud ante la realidad objetiva- está tomado de Bajtin. Por cronotopo se entiende una categoría formal y de contenido donde se expresa la función tiempo-espacio en un todo consciente y coherente. Tiempo y espacio se hacen artísticamente visibles en el cronotopo, al determinar éste la imagen del ser humano en el mundo. Esta imagen esencialmente cronotópica es determinante en la constitución del género literario activado y también en la configuración del argumento. En este sentido, el cronotopo es el centro organizador de los principales hechos argumentales de la novela, puesto que en él estos se concretan y materializan (460). Dar cuenta del cronotopo de una novela exige, por lo tanto, poder captar su "plenitud factual", esto es, hacer interactuar "su aspecto material externo, su texto, el mundo representado en ella, el autor-creador y el oyente lector" (465).

Al hablar, entonces, de cronotopo de la exclusión, se está pensando en las diversas formas que adopta la construcción de un marco de inclusiones 
y exclusiones en determinados períodos y contextos históricos. Formas de exclusión serían, por ejemplo, la segregación social en sus variadas expresiones, la miseria, el clasismo, el racismo, entre otras manifestaciones de desintegración y violencia social ${ }^{4}$.

Por otro lado, la postulación de una cronotopía permite establecer, en parte, lo que Antonio Cornejo Polar define como la "imagen hermenéutica del mundo" que todo texto de ficción desarrolla. Esto exige, entre otros procedimientos intentar "iluminar la índole, filiación y significado" de dicha imagen (8).

\section{CRISIS DEL DISCURSO NACIONALISTA EN EL DISCURSO DEL 38}

Lo que aquí se propone es que, en el contexto del cronotopo postulado, la imagen hermenéutica del mundo que estas novelas componen pone en crisis uno de los soportes paradigmáticos en los que se fundamenta el concepto de nación, esto es, el proyecto de integración social. Según Bernardo Subercaseaux, entre 1900 y 1930, el nacionalismo, inserto en el contexto de la modernización y con su énfasis en la integración, intentaba neutralizar la progresiva desintegración de las estructuras tradicionales, producto de los cambios que experimentaba una sociedad tradicional y oligárquica en crisis y en vías de modernización. Inspirado en una matriz cívica, racionalista y universal, el Estado y la elite ilustrada promovieron una ideología de la homogeneidad, cuyo fin era estimular la cohesión social en todos los ámbitos del entramado social de la nación (Subercaseux, Historia 158-159). Dicha ideología de la homogeneidad fue "una ideología abocada a la tarea de construir una nación de ciudadanos cuyos miembros debían estar unidos por una sola cultura y por un conjunto de creencias, valores y tradiciones compartidas" (Subercaseux, Chile 544). Se fue gestionando así un sentido de pertenencia y un "nosotros" integrador que, según Benedict Anderson, se traduce en un tipo de comunidad imaginada, puesto que "independiente de la desigualdad

4 Para estudiar las diversas formas de exclusión que se han producido en América Latina es pertinente el texto: Dinámicas de exclusión e inclusión en América Latina (Editores: Alejandra Bottinelli / Carolina Gainza / Juan Pablo Iglesias).Santiago: Centro de Estudios Latinoamericanos. Facultad de Filosofía y Humanidades, Universidad de Chile. 2005. 
y la explotación que en efecto puedan prevalecer en cada caso, la nación se concibe siempre como un compañerismo profundo, horizontal"(25).

En oposición a este paradigma social y discursivo, la narrativa del $38 \mathrm{se}$ erige como el diseño negativo de tal pretensión unificadora. La imagen hermeneútica del mundo se traduce en la representación de la ciudad de Santiago como una entidad compartimentalizada, donde determinados sectores no parecen formar parte de un Chile en vías de modernización; ciudad de castas y clases sociales en abierta disputa. De esta forma, la comunidad imaginada por el discurso nacionalista de las primeras décadas revela su contracara y su fractura interior, mostrando al ser humano acosado y en lucha con diversas formas de opresión, fundamentalmente social y política.

La novela del 38 entrará en conexión con otro tipo de discurso que comienza a adquirir presencia en el contexto social chileno desde finales del XIX, el que dejará al descubierto la crisis del modelo liberal de nación y sus aspiraciones fallidas de integración social. El desplazamiento desde las zonas rurales a la capital y "la masificación de la ciudad", en términos de José Luis Romero (292), creará un escenario político diferente donde los nuevos grupos sociales demandarán mayor participación:

"La actividad minera, el desarrollo de los ferrocarriles, la intensificación del movimiento portuario, la modernización de las ciudades, el surgimiento de nuevas industrias y actividades de toda índole acentuarán el proceso de crecimiento del proletariado. Así este sector estimado en 150.000 hombres en 1890 y en 200.000 a 250.000 en 1900, sobrepasa los 350.000 en 1920" (Ortiz 73).

En ese contexto, los nuevos habitantes de la ciudad experimentarán serias dificultades de inserción laboral y social, lo cual fue generando una forma de solidaridad que fue clave para sus posteriores demandas de participación colectiva.

Cabe destacar que desde finales del siglo XIX se conjugaron una serie de factores que transformaron los problemas que Chile sufría en una "cuestión social". Tales factores son la creciente industrialización, una fuerte urbanización sin crecimiento orgánico, la indiferencia de las clases dirigentes ante los problemas del pueblo y finalmente una clase trabajadora agotada de esperar que el Estado le otorgara la ayuda requerida. Ya a comienzos del XX surgen diversos movimientos que hacen de la cuestión social un tema de interés nacional. El debate se abre así a las diversas esferas públicas, a partir de propuestas que, a pesar de sus diferencias de enfoque, se abocaron 
a la tarea de darle una solución a los problemas derivados de la cuestión social. Ya en las primeras décadas del siglo la cuestión social se convirtió en un tema de interés gubernamental. Más adelante, y a medida que el proletariado fue adquiriendo mayor definición en el aspecto ideológico y fue posible contextualizar mejor sus aspiraciones, se generaron iniciativas que permitieron disminuir las tensiones sociales. De esta forma, la expresión "cuestión social" (que fue un concepto elaborado por la elite) dio paso a otras definiciones, de carácter más bien confrontacional, que representaban de manera más adecuada los problemas existentes entre las clases dirigentes y los trabajadores.

Este escenario tiene su expresión política en la elección de Arturo Alessandri Palma en 1920, quien alcanzó el poder gracias al apoyo popular y cuya campaña se caracterizó por un programa de acción reformista, por una disposición antioligárquica y por un afán de mayor justicia social. Sin embargo, será en el gobierno de Pedro Aguirre Cerda, elegido en 1938, como representante del Frente Popular, donde se producirán cambios sustantivos en el espectro político. La victoria del Frente Popular fue "el hecho distintivo de la época (...) Chile ya no sería más objeto, sino sujeto de la historia (...) pusimos algo de nuestra alma en esa lucha y nos sentimos parte del pueblo. Nos impulsaba un ansia apasionada de cambiar la vida nacional" (Teitelboim, La generación 118). La narrativa del 38 hará suyo este discurso de reivindicación, denunciando las injusticias sociales y la exclusión sufrida por gran parte de la sociedad chilena. Sus demandas entrarán en resonancia con los más importantes fenómenos mundiales, como fue la crisis mundial de 1928 y particularmente la Guerra Civil española. Según Eduardo Anguita:

\footnotetext{
"Aunque el año 38 nos aglutinó, en verdad fue el año 36 el primer aguijonazo: la Guerra Civil de España. Todos, escritores y artistas, mayores que nosotros, o los de nuestra edad, nos alineamos junto a la España republicana. Su tragedia fue, sin duda, una semilla que fructificó en la lucha de otros pueblos: en la Segunda Guerra Mundial, en Cuba, en Vietnam" (19).
}

Por su parte, Luis Oyarzún señala que la Guerra Civil española generó un efecto psicológico de impredecibles consecuencias, debido a que obligó a los jóvenes a un examen de conciencia y a una toma de posición, ya que "no era una guerra civil como las otras. Era, en verdad, el primer episodio inequívoco de la gran división del mundo" (184). 
Este contexto social, espiritual y colectivo, donde se forjó el temple literario de la generación del 38, se vio reforzado por un acentuado dinamismo cultural que vivía el país, estimulado por la creación de la Alianza de Intelectuales para la defensa de la Cultura (1937-1940), la modernización del Conservatorio Nacional de Música y otros hitos culturales de la época (Teitelboim, Sobre 18). Tal impulso colectivo estimulará a la generación del 38 a fortalecer sus demandas de justicia a través de una literatura comprometida con la realidad, no solo local sino con la del mundo, pues, como dice Fernando Alegría en 1962: "buscar la chilenidad” se entenderá entonces como el "buscar lo que une a los hombres de todas partes, no aquello que los separe" (64).

\section{UNA EXPRESIÓN DRAMÁTICA DE LA BARRIADA: PRIMERA MODALIDAD CRONOTÓPICA DE LA EXCLUSIÓN}

Una primera modalidad del cronotopo de exclusión la ofrece la novela $\mathrm{An}$ gurrientos, de Juan Godoy, publicada en 1940. La representación de mundo desarrolla a cabalidad los tópicos que caracterizan lo que se definió como novela proletaria, entendiendo por ello "el correlato de la vida popular que incluye el arrabal, las barriadas obreras urbanas y suburbanas, el registro de la delincuencia, el vicio, de los humildes, (...) de toda ese magma humano que acintura las ciudades y las prolonga en colgajos harapientos" (Uriarte 93). En consonancia con esta definición, esta primera modalidad de exclusión apunta al radical aislamiento que sufren los sectores marginales de la sociedad chilena. Remite a los enclaves sociales donde el progreso y el desarrollo han estado ajenos, lo que convierte en imposible cualquier posibilidad de superar la determinación negativa que sobre dichos sectores pesa. En este sentido, la primera modalidad de exclusión refuerza la idea de la privación de espacios, condiciones y habilidades para el desarrollo integral del ser humano y de la convivencia social.

El espacio geográfico focalizado en Angurrientos es El Salto, en Conchalí, territorio en ese entonces cuasi rural donde predomina la miseria, el hambre, la violencia familiar, el alcoholismo y la enfermedad. Según Raúl Silva Castro, "de los personajes de este autor, en general, podría decirse que, salvo excepciones, están alimentados con desperdicios y hablan como si estos se les hubiesen metido en las almas" (327). El abandono que sufren las capas populares es denunciado por el narrador al referirse a la mortandad 
del pueblo, producto de las condiciones de vida miserable: "La peste viruela hacía estragos en la población. En el hospital San José, hombres de torso desnudo cargaban como a cuartos de animales sacrificados, los cadáveres de los apestados, de ese recinto al pudridero común del Cementerio General" (106).

En este contexto de desarraigo y exclusión, toda alusión a un posible sentido de pertenencia a una nación integradora está contaminada por la contradicción. Elocuente, al respecto, es el hecho de que al describir el narrador el estado en que se encontraban unos canteros, enfatice que "ellos eran huérfanos en su propia tierra y andaban perdidos y nada tenían. Leguas y leguas. De mineral en mineral. En campamentos de la más espantosa soledad, donde trabajaban sus días (...) vividos con la historia sorda de la tierra chilena a cuesta" (89) Esta sensación de despertenencia al país coincide con la percepción de que la legalidad de la nación es diferente a la legalidad de las clases populares ${ }^{5}$. Al respecto, uno de los personajes, el sargento Ovalle, confiesa que "la parte más noble de Chile vive fuera de la ley, porque no vive su ley y la teme. Los otros se hicieron su ley, amparando bajo ella su mediocridad. Hacen cumplir al pueblo algo que no conoce el pueblo, ajeno al pueblo, sin su deseo" (84). Por otro lado, es significativo que quienes entonan cuecas chilenas y marchas de la Guerra del Pacífico sean justamente los canteros con crisis de pertenencia y que una mendiga cante una tonada en medio de un pútrido basural (96). Estas marcas de identidad internalizadas en el pueblo devienen contradictorias en un contexto de país donde dichos personajes no tienen cabida. Paradigmático es el caso del personaje Edmundo, cuyo deseo es ayudar a la población a superar el alcoholismo generalizado y a luchar por sus derechos. Para ello ha entrado a la Universidad -situación inédita en ese contexto- pero, dadas las enormes dificultades que ello significa, no logra concluir sus estudios y termina finalmente hundido también en el alcoholismo. Desde su frustración se lamenta por la falta de posibilidades que tiene el pueblo para salir de su condición de abandono y subraya la necesidad de buscar en sí mismo la respuesta: "Dios está irremediablemente enterrado para los pobres, pero los hombres andan en busca del buen Dios. En tanto le hallan, yo me arrodillo delante de mí mismo como ante mi propio Dios" (27). Edmundo desarrolla al mismo tiempo una tesis

${ }^{5}$ Englobando en este concepto a "hombres, mujeres y niños afectados por situaciones de explotación, represión y exclusión, que construyen, a partir de ellas, redes de identidad y de acción específicas" (Salazar 92). 
sobre la conocida tristeza del chileno: "Viene un inglés y nos dice: Ustedes son un pueblo triste; viene un francés y nos dice: ustedes son un pueblo triste (...) no se puede ser triste sin haber vivido antes una tragedia. ¿Cuál fue nuestra gran tragedia? ¿Depusimos las armas sin agonía, sin lucha? Los pueblos tristes son los pueblos de esclavos" (44).

El contexto descrito en la novela entra en consonancia con el diagnóstico social realizado por Salvador Allende en el año 1940, quien, siendo ministro de salud del gobierno de Pedro Aguirre Cerda, planteaba que "las condiciones miserables del pueblo se evidencian en su pésima alimentación, la explotación que sobre él recae y la falta absoluta de distracciones. Por eso ir a la cantina constituye para él la aparente solución de esos problemas. En la cantina encuentra luz, calor y amigos para distraerse y olvidar su miseria" (51). Algunos años antes, en 1911, Tancredo Pinochet apostaba a que: "Si se suprime el conventillo y vive el obrero en habitaciones sanas y confortables, quedará desierta la taberna; si se suprime la taberna, el obrero sobrio, con abundancia, repudiará el conventillo" (43).

En Angurrientos la pobreza, el alcoholismo y la falta de oportunidades redundan en que las sangrientas peleas de gallo que ocurren en El Salto sean la única entretención que saca a la gente de su letargo. Tal forma de esparcimiento parece ser, al mismo tiempo, la posibilidad de una experiencia de comunidad en medio de su desgracia social: "Los espíritus de los galleros habían creado, por sobre sus cabezas, fundiéndose, un alma colectiva. Y hablaba cada cual con la intimidad de un yo con su alma" (67). Sin embargo, dicha forma de convivencia se ve amenazada por elementos exógenos a esa precaria comunidad. Es elocuente que sea el gallo llamado Condorito -nombre que remite a uno de los personajes representativos del imaginario nacional popular- el que termine destrozado por el gallo de unos norteamericanos que pululan por la población, pues, como enfatiza el narrador: "Los gallos de los yanquis eran invencibles. Sucedía lo que en todas las ruedas. Una larga y angosta guirnalda de triunfo para los gringos" (60). La muerte de Condorito, en un contexto que carece de verosimilitud estética, es una metáfora un tanto forzada que el texto desarrolla respecto a la explotación y la condición de precariedad que sufre el país, por culpa del imperialismo norteamericano. Desde su trinchera ideológica, Juan Godoy pensaba que los grandes monopolios y el imperialismo enquistados en el país eran la principal causa de la pobreza generalizada. En este sentido comulga con quienes consideraban, en la década de los 40, que: 
"Los consorcios extranjeros controlan las principales riquezas del país: salitre, cobre, hierro, azufre, etc. (...) Una vez que el imperialismo alemán se derrumba, entra en acción el imperialismo norteamericano. La Cosach implicó la entrega del 50\% de las utilidades del salitre a los consorcios yanquees. Sus inversiones alcanzaron en poco tiempo la suma de 700 millones de dólares" (Jobet 19).

Sin embargo, no es solo el imperialismo norteamericano el denunciado en el texto, sino toda forma de explotación que subyugue al ser humano. Un personaje, cuyo apodo es Cara de Ángel, argumenta que:

\begin{abstract}
"Los imperialismos europeos nos impusieron su cultura, y son engañosas cadenas con que las culturas extranjeras nos entregan a la esclavitud y servidumbre, a la dependencia espiritual con lazos de seda; prefiramos lo incierto de nuestra propia vida a lo cierto de vidas extrañas, porque esa certeza es, para nosotros, sumisión y esclavitud" (92).
\end{abstract}

La denuncia realizada por el personaje no parece tener cabida en un mundo social que determina fatalmente a los personajes, anulando cualquier posibilidad de transformación personal y colectiva. Cada uno es caracterizado a partir de las deficiencias morales y espirituales responsables de la mencionada apatía. Este es el caso, por ejemplo, del gallero Augusto Caorili -personaje violento y egoísta que posee como único horizonte de vida la sangre y el devenir de las peleas de gallo- y de Alejandro: cantero que labra esculturas de Santos y Vírgenes en las tumbas, como una forma de acompañar su sentimiento de absoluto desarraigo con la realidad. En esta galería de seres desolados es Wanda, objeto del deseo de todos los hombres, el personaje donde se concentra, de manera alienante, la frustración y el extravío de la conciencia. La joven, que ha sido descrita como una criatura angelical de ojos azules y cabello dorado, se convierte, al final de la novela, en portadora de una pulsión de muerte donde erotismo y sangre se funden en un acto de venganza delirante: "Extrajo de un cofre la navaja de afeitar del cura (...) Cogió el gallo blandamente. Lo maniató de las espuelas. Apretó las patas del giro de riñas entre sus muslos desnudos y ahogándolo con una mano, empezó febrilmente a degollarlo. Sangre caliente bañada de acre, dulce opresión sus muslos mórbidos" (154).

La novela de Juan Godoy revela la función de crítica social que, según los miembros del 38, debe cumplir la literatura y se ofrece como un "testimonio de la angustia humana frente a la miseria artificial producida por un sistema 
económico capitalista" (de la Fuente 143). En vez de una trama convencional, la estructura narrativa de Angurrientos articula, más bien, escenas donde la miseria humana es expuesta en imágenes y situaciones casi siempre extremas. En el imaginario construido por Angurrientos se observa la adscripción de Juan Godoy a los principios del escritor proletario, que según Máximo Gorki, se traducen en "un odio activo del escritor a todo lo que oprime al hombre tanto desde fuera como desde dentro, de todo lo que le impide el libre desarrollo y crecimiento de sus capacidades" (188). La palabra Angurriento dio origen al angurrientismo, vocablo que viene de "angurria", que significa hambre canina, hambre del pueblo (Montes 215). En el plano espiritual significa el despertar social y político del pueblo (Plath 203). En este sentido, "el angurrientismo es una negación del pasado, reconociéndolo como tal pasado. Y una afirmación inmensa del porvenir" (Godoy El Angurrientismo 17). Sin embargo, dicha aspiración no queda reflejada en el verosímil de la novela, pues la degradación social y la indiferencia de la población anulan finalmente las expectativas de cambio. El mundo descrito evidencia que en 1940, año de la publicación de Angurrientos, la situación no había cambiado mucho respecto a dos décadas anteriores, cuando Luis Emilio Recabarren denunciaba, en 1910, que mientras la clase burguesa progresaba desmedidamente, "las clases populares vivían todavía esclavas y encadenadas al orden económico, con la cadena del salario, que es su miseria; en el orden político con la cadena del cohecho, del fraude y en el orden social con la cadena de la ignorancia y de sus vicios, que les anulan para ser considerados útiles a la sociedad en que vivimos".

\section{EL CONVENTILLO COMO EPICENTRO DE UNA PRAXIS REVO- LUCIONARIA: SEGUNDA MODALIDAD CRONOTÓPICA DE LA EXCLUSIÓN}

La segunda modalidad del cronotopo de exclusión está presente en La sangre y la esperanza, de Nicomedes Guzmán (1943). En comparación con la primera modalidad de exclusión antes vista, que se caracteriza por el radical aislamiento del sector de realidad descrito y por el determinismo fatal que lo define, ahora la representación se localiza en un espacio más definido y 
acotado, como es el conventillo, el que entra en confrontación directa con la realidad exterior al mismo. La miseria social y los excluidos del desarrollo se concentran en este espacio simbólico que se erige en expresión tangible de la segregación social. Sin embargo, y a diferencia de lo que ocurre en Angurrientos, en este modelo de exclusión se logra salvar la determinación negativa que paraliza a los sectores populares, lo que se traduce en la superación de los límites del reducto de supervivencia (el conventillo) y en la confrontación con ese Otro que segrega y excluye.

El núcleo del relato de La sangre y la esperanza lo compone la familia de Guillermo Quilodrán, padre del narrador y empleado tranviario. El sector representado es, básicamente, un conventillo del barrio Mapocho, lugar donde se expresa un mundo donde convive la miseria (prostitución, violencia sexual, robo, alcoholismo, abulia, entre otras lacras sociales) con la dignidad de quienes luchan por cambiar la realidad que los oprime (líderes sindicales, mujeres trabajadoras, familias sólidamente constituidas, profesores idealistas, jóvenes revolucionarios, entre otros personajes en quienes habita la utopía). El título de la novela se nutre, justamente, de esta vocación de justicia revolucionaria que impulsa al pueblo a salir adelante y conquistar su futuro: " $\mathrm{La}$ sangre como expresión de las pasiones, el sufrimiento, la felonía (....) y la esperanza como forma biosocial de convalecencia que se aferra y desarrolla la paciencia y la permanencia popular para superar algún día la miserable condición de los asalariados" (de la Fuente 151).

El contexto histórico alrededor del cual transcurre la historia narrada es la huelga de los tranviarios de la década de 1920, con el apoyo de la Federación Obrera de Chile. Cabe recordar que el reagrupamiento en Chile de la clase obrera empezó el mismo año del centenario y que quienes inician este proceso son los ferroviarios. Dado que la Empresa decidió retener el 10\% de los sueldos por un supuesto déficit en sus balances, los obreros optaron por paralizar y demandar para que se les pagara lo que se les adeudaba. En 1919, los tribunales acogieron favorablemente dicha demanda y puesto que la defensa necesitaba organizarse, "nació en Santiago, el 18 de septiembre de 1909, la Federación Obrera de Chile" (Ortiz 183). A nivel ficcional, dicho referente histórico es, sin embargo, solo el reflejo de la situación de un país que se debate en una profunda crisis social: "La cesantía en la zona del salitre era pavorosa. La capital parecía estremecerse bajo el peso de la humanidad mísera y hambrienta" (235).

Según Nicomedes Guzmán, el imperativo que alentó su trabajo fue trascender lo que definió como la traición literaria y estética con la que la 
literatura burguesa (por ejemplo El roto, de Joaquín Edwards Bello) había estigmatizado el espacio del conventillo. La idea era narrarlo desde dentro y otorgarle la dignidad merecida. Debe recordarse que en 1872, el intendente de Santiago, don Benjamín Vicuña Mackenna, buscaba separar, mediante la creación de un "camino de cintura", a la "ciudad propia", es decir aislar a la ciudad decente, bella y letrada, de los reductos de miseria y suciedad que se mezclaban con ella. Según el Plan Regulador propuesto: "El camino de cintura establecerá alrededor de los centros poblados una especie de cordón sanitario por medio de sus plantaciones, contra las influencias pestilenciales de los arrabales (...) esta ciudad completamente bárbara, injertada en la culta capital de Chile y que tiene casi la misma área de lo que puede decirse forma Santiago propio" (8). Ya entrado el siglo XX, el conventillo fue el tipo de infravivienda más difundida entre las clases populares:

"Su existencia fue producto de la acción deliberada de los antiguos propietarios de casas ubicadas en barrios centrales de la ciudad de Santiago que las subdividieron y comenzaron a arrendar las habitaciones en forma separada. El proceso se da a partir del abandono de los grupos aristocráticos de esas locaciones, los que posteriormente reacondicionaban esas viviendas para obtener beneficios económicos" (Hidalgo y Sánchez 52).

Tales espacios de marginalidad, sin alumbrado público, con piso de tierra, sin agua potable y sin baños fueron asociados a la suciedad, la promiscuidad, la enfermedad y la delincuencia. Como plantea Lucía Guerra en su excelente estudio de Los hombres obscuros (1939), del mismo Guzmán, la miseria y la exclusión convierten al espacio del conventillo en desecho de la nación, lo que pulveriza cualquier discurso de integración social (123-124). Lo anterior entra en consonancia con los planteamientos de Henri Lefebvre, quien, en $L a$ revolución urbana, señala que lo represivo que tiene la urbe "proviene de lo que en ella se esconde, y de la resolución de mantener escondidos los dramas, las violencias latentes, la muerte" (127). Se produce así una tensión irresuelta entre la isotopía, como el lugar de lo idéntico y el orden próximo, y la heterorotopía, esto es, "el otro lugar y el lugar de lo otro, excluido e implicado a la vez. Orden lejano" (Lefebvre 128). En La sangre y la esperanza, el orden exterior al conventillo penetra en él únicamente para reprimir los focos de delincuencia y para "cooperar" con la higiene de la ciudad. Según Julio César Jobet, en un artículo de la revista Rumbo, de 1940, había ese mismo año en Santiago más de 3.000 conventillos donde vivían más de 250.000 personas, 
siendo habitual que en una misma pieza vivieran hasta doce personas (22). Pero, los conventillos se convirtieron también, en 1922, en el epicentro de protestas organizadas, lo que se tradujo en la huelga de arriendos en 300 de ellos. Dicha huelga fue ampliamente apoyada por el Frente Popular.

La novela incorpora este impulso revolucionario como también la desilusión ante un gobierno que ha abandonado a los trabajadores. Solo se tienen a ellos mismos, pues como dice uno de los personajes: "La verdad es que el pueblo parece no necesitar sino de buenos dirigentes que pongan su esfuerzo al servicio de la unidad. ¡Los líderes, una vez que se levantan a costillas nuestras, olvidan al pueblo"! (260). De esta forma, la fuerza social alcanzará por fin la virtud del colectivo. Como se aprecia en uno de sus cantos: "unión / unión / hasta obtener el triunfo de la paz. Soy comunista / viva la unión / social" (75). El marxismo y la lucha de clases serán su inspiración para alcanzar la dignidad buscada.

La huelga de los tranviarios resulta exitosa y esto les otorga valor para salir de los conventillos a luchar por sus demandas. Por calle Bulnes se dirigen a la Alameda hasta llegar a los pies del monumento a O'Higgins, lugar donde el joven revolucionario Abel Justiniano toma la palabra para apoyar la marcha. El conventillo ha roto los límites de su encierro y ha alcanzado el centro de Santiago con toda su simbología y emblemas representativos de la nación. La represión es inmediata y no discrimina a niños ni mujeres. Al final de la jornada, "la autoridad y la traición habían triunfado" (266). A pesar de ello, el pueblo ha adquirido una conciencia de lucha: "Gastamos nuestra fe creyendo promesas y programas. Perdemos el tiempo, cuando lo único que merece nuestra fe es la revolución" (267). Ni la feroz represión ni la sangre vertida clausurarán las expectativas del pueblo, ya "que al pueblo no se le engaña. No puede engañársele. Porque el pueblo es agua, y sal, y harina de verdad" (237-238). A pesar de que el joven revolucionario es acribillado por la espalda, su pareja, quien es hermana del narrador, será madre de un niño en el que se centra la esperanza y la utopía por un mundo mejor. El amor al servicio de la praxis política y el motivo de la mujer proletaria se han fundido en el deseo revolucionario. Guzmán ha hecho suyo el postulado de Zhdánov, quien en el primer congreso de escritores soviéticos, en 1934, postulaba buscar la heroicidad en el mundo obrero y generar un romanticismo revolucionario enfocado en el presente y en la lucha social. Teniendo como referente a Máximo Gorki, Zhdánov planteaba que el escritor proletario debía ayudar a la construcción del socialismo, con el apoyo de la doctrina de Marx, Engels, Stalin y Lenin. Al final del discurso, sus postulados dirigidos al escritor 
proletario son enfáticos al señalar: "¡Sed los organizadores más activos en la reeducación de la conciencia de las gentes en el espíritu del socialismo! ¡Situaos en las primeras filas de los combatientes por una sociedad socialista sin clases!" (402). La proclama de Zhdánov encarna en lo que Nicomedes Guzmán considera el imperativo moral de un escritor, esto es, ser fiel a la realidad social y política que lo circunda. Como él mismo señala: "Los hechos políticos que figuran en las novelas son parte de la vida misma. El autor tiene la obligación de interpretar la vida y si esta vida implica la lucha social, el autor, fiel a los asuntos humanos no puede desconectarla a trueque de falsear la realidad" (Guzmán, Literatura 13). Dicha posición ante el arte y la literatura revela la necesidad del escritor por denunciar la explotación que caracteriza al orden burgués. Tal función es desplegada en una estructura narrativa abigarrada de discursos, donde la secuencia de hechos narrados se enriquece con textos poéticos, elementos visuales, recortes de crónicas, letras de canciones, etc. A diferencia de Angurrientos, la novela de Nicomedes Guzmán logra construir una peripecia con solidez narrativa, lo que ayuda a la constitución de una visión de mundo coherente.

Como puede apreciarse, tanto en Angurrientos como en La sangre y la esperanza, el discurso de las ideas desplegado refuerza los conceptos de segregación y exclusión. Por discurso de las ideas se entiende aquí una concepción del arte narrativo que considera que "el fin del desarrollo narrativo no es exponer series de acciones verosímiles, sino una experiencia o una concepción del mundo que aquellas acciones o su desenlace puedan convalidar. El discurso sobre hechos y acciones desarrolla, por tanto, implícitamente otro discurso, el de las ideas; y entre estos dos discursos, entre estas dos cadenas, se desarrolla la totalidad de la narración" (Segre 355). En el caso de las dos novelas analizadas, este discurso de las ideas entra en fructífero diálogo con el libro La muralla enterrada, de Carlos Franz. Este autor plantea que en el imaginario literario de la ciudad de Santiago se observa la presencia de un muro invisible que separa y secciona la ciudad en un conjunto de ciudadelas, entendiendo por este concepto una pequeña urbe dentro de la otra (188). La separación más evidente la ofrece la oposición centro / barrio Mapocho (o barrio La Chimba), donde "el centro representa nuestra razón amurallada, nuestro corazón defendido, la Chimba esconde nuestro vientre hambriento" (33). Se refiere Franz a la existencia, en el barrio La Chimba, de lugares tales como el cementerio y el manicomio; espacios de reclusión opuestos a la legalidad visible que el centro de Santiago representa. De esta forma, La Chimba, además del reverso del centro se ofrece como una ciudad paralela 
al otro lado del río, lugar donde se experimenta una particular modalidad de exclusión. Al interior de Santiago, ciudadelas aisladas como La Chimba, el Jardín, el Matadero, el barrio chino, se ignoran mutuamente y, a la vez, se vinculan forzadamente con el centro de la capital (193). La muralla invisible que segrega y excluye convierte a los sujetos citadinos en seres que viven la experiencia del extrañamiento cada vez que transitan por un espacio que no les es propio. Traspasar la muralla invisible es por ello una vivencia donde se hace presente un sentimiento de ajenidad, sentimiento que encarna en los cités, los conventillos, las pensiones: "La ética de la muralla enterrada, que domina el Santiago imaginario, castiga a quienes tratan de fugarse de su lugar asignado" (197).

El estudio de Carlos Franz enriquece el imaginario de la ciudad desplegado en las novelas analizadas anteriormente. Tanto en Angurrientos como en La sangre y la esperanza la ciudad, entendida como el lugar donde se despliega el cronotopo de la exclusión, se revela como una topografía donde la cotidianeidad de los personajes se halla comprometida con las consecuencias de esa muralla enterrada e invisible. En este sentido, que los personajes hayan nacido en Conchalí, en medio de la absoluta miseria (como es el caso de Angurrientos) o en un conventillo del barrio Mapocho (como en $\mathrm{La}$ sangre y la esperanza) pasa a ser determinante en la configuración de sus concepciones de mundo.

\section{FRICCIÓN DE CLASES Y ADQUISICIÓN DE CONCIENCIA: TERCERA MODALIDAD CRONOTÓPICA DE LA EXCLUSIÓN}

Una tercera modalidad cronotópica de la exclusión se encuentra en la novela El Tiempo banal, de Guillermo Atías (1951). El tipo de exclusión a la que se alude aquí tiene como fundamento el problema del clasismo arraigado en la sociedad chilena ${ }^{7}$. En este sentido, el clasismo se erige como una causal

7 La mentalidad clasista de parte de la sociedad chilena ha sido denunciada, entre otros, por artistas como Roberto Matta (coetáneo de Guillermo Atías), quien señala: "Porque la base -y aquí es donde podría representar el sentimiento que yo tenía sobre el problema de Chile- es que yo nací en una especie de clase chilena que es la responsable de esto, es decir, la que ha metido en la cabeza a la historia de Chile que hay "gente" y hay "rotos". Ahora, yo me fui de Chile para huir de esto. Porque no podía soportar vivir en una especie de privilegio desfachatado, en que las cosas eran desde el principio así. Me acuerdo que uno iba a la universidad y tenía todos los 
importante de exclusión de quienes no pertenecen a esa esfera social que descalifica, segrega y excluye a quienes no pertenecen a ella. Opera aquí un concepto de exclusión, donde los privilegios de una determinada esfera social contrastan, de manera radical, con las posibilidades de otros sectores del entramado nacional. Más allá del tema de las privaciones económicas $\mathrm{y}$ de los bienes que satisfagan las necesidades humanas esenciales, lo que cuenta aquí es un proceso de descalificación social y de tensión generalizada entre las clases sociales.

Respecto a El tiempo banal, el síntoma del clasismo se expresa en la compleja interacción de tres clases sociales: la alta, representada por los aristócratas Fernando Blanco, su esposa y el resto de la familia, la media, representada básicamente por un profesor de castellano de nombre Alberto, y la baja, representada por Cora, un cartero, su esposa y un delincuente apodado el Chano. Cada uno de estos grupos habita sectores de la ciudad diferenciados y excluyentes: los aristócratas viven en una mansión del "barrio alto", el profesor de castellano a pocas cuadras del centro y los exponentes del pueblo en una vieja casona de la calle Compañía, lugar que alguna vez perteneció a una familia adinerada, pero que ahora se arrienda por piezas, como una suerte de conventillo, a gente de escasos recursos.

En la novela de Atías, las características y costumbres de cada grupo social son descritas con precisión y detalle. En el caso de los aristócratas, su rutina habitual consiste en bajar al centro en su lujoso Oldsmobile, para llegar a sus destinos, que son siempre la Bolsa de Comercio o el Teatro Municipal; más allá está lo desconocido, donde no conviene aventurarse. Sin embargo, después de una función en el Municipal y retornando a su barrio, esta asepsia visual y social se contamina al ver cómo unas prostitutas se exhiben a los automovilistas. La pareja se incomoda por un instante, pero de inmediato logra superar el sentimiento de temor, apelando a una evidencia indesmentible: "Eran ricos, fue una sensación simultánea que los asaltó. Con un ligero agrado, se extendieron en esos cojines excesivamente blandos ¿qué podrían temer?” (74).

privilegios. Yo sabía que iba a tener trabajo cuando saliera de la universidad. Y había tipos que venían de la provincia que vivían en un cuarto al lado de la Estación Central y que no podían estar seguros de esto. Jamás estos que se decían "la gente" les habrían dado trabajo a estos tipos, porque la situación era la casta. Hacían bailes donde no los invitaban, y yo -invitado a estos bailes- veía que estos tipos iban a la universidad pero no los invitaban jamás” (Roberto Matta 14). 
Según el exitoso aristócrata, dos aspectos negativos enturbian la ciudad: "esos extranjeros, poseedores de hábitos singulares, que se colaban en todas partes; que le disputaban los negocios, haciendo uso de una tenacidad poco elegante. Por otra parte existía el pueblo, las asociaciones populares, cada vez más insolentes, que molestaban con sus desfiles, y que afeaban la ciudad escribiendo en las calles con letras transgresoras" (29). Su desprecio por las clases bajas corre en paralelo con su absoluta falta de conciencia por la explotación que sufren los campesinos en su fundo del sur, a manos de un inescrupuloso administrador.

En lo que concierne a Alberto, profesor de castellano y representante de la clase media, su itinerario cotidiano se traduce en el vagar por el centro antes de dirigirse a la Estación Central en busca de aventuras. La perspectiva ideológica del texto evidencia un rechazo a la falta de consistencia que acusan los representantes de esta clase social. Alberto encarna la ausencia de raíces de un sector de la sociedad que se caracteriza por su vacío existencial y por la ausencia de proyectos vitales. El tiempo banal, enunciado que da el título al libro, remite también a la falta de conciencia del otro: "El tiempo banal. Existe un tiempo de la nada, cuando los desarrollos se gestan (...) Todo acto resulta arbitrario cuando se trata de forzar ese instante incierto" (42). A pesar de ser transversal a las tres clases sociales, el tiempo banal parece concentrarse en mayor medida en la clase media representada por Alberto: "Alberto se entregaba a la seducción de ese tiempo banal. Dejaba que su existencia flotara entre esa muchedumbre que no cesaba de ir y venir frente a él" (9).

En sus paseos hacia la Estación Central, Alberto conoce a la poeta Cora y accede así a la realidad del pueblo. Ella se interesa en él, a pesar de que, según señala el narrador con un claro juicio de valor ante el descompromiso social: "Un hombre de esta especie provoca una infinita piedad o una repulsión violenta" (48).

Cabe destacar que la crítica social que se advierte en El Tiempo banal también alcanza a la esfera del pueblo. Este es el caso de la decadente poeta Cora, quien desaprovecha la vida entre el alcohol y la ausencia de sueños. También el cartero y su esposa Luisa han construido un mundo de a dos, a resguardo de las vicisitudes de la realidad exterior. Por su parte el Chano es el típico delincuente cuyo único propósito es ganar grandes sumas de dinero a cualquier precio. Además de no asumir ni aceptar su condición de clase baja, su arribismo desmesurado y su mitomanía lo harán embarcarse en un eventual tráfico de drogas y para ello robará y cometerá un crimen. La crítica social también recae en Luisa, la inconsistente esposa del cartero, quien finalmente 
huye con el Chano, para vivir la aventura de una vida otra, más excitante. Para ello abandona al cartero, personaje valorado especialmente por el narrador, pues, a pesar de vivir al principio desligado de los problemas sociales, a diferencia del Chano no reniega de la clase trabajadora de la cual proviene: "Hay una gran certidumbre en todo lo que ese hombre hace" (35).

La crítica social generalizada que Atías desarrolla en El tiempo banal apunta a la imposibilidad del sujeto citadino de experimentar la ciudad como unidad de integración. Tal sintomatología es trabajada, en un nivel extraficcional, por el historiador José Bengoa, en su libro La comunidad perdida (1996). El autor considera que "en Chile no se constituyó nunca, ni se ha constituido una cultura ciudadana" (57), dada la persistente nostalgia que la ciudad tiene de un pasado mítico rural del cual no puede desprenderse:

"La identidad de este país ha estado principal y casi exclusivamente basada en un modelo cultural proveniente de la antigua experiencia rural de la sociedad. La ruralidad, verdadera o aparente, ha sido el modelo de identidad nacional, el modelo de convivencia nacional, el modelo valórico que ha unido, que ha interpretado a los chilenos, en especial a su clase media y obviamente a sus clases populares" (57).

Justamente sería esta condición del habitar la ciudad la principal causa del autoritarismo, el afán de dominación y la necesidad de subordinar al otro. Al guiarse la ciudad por pautas rurales se reactualiza, a pesar de los intentos de modernización, un patrón de conducta que genera un trato "entre ricos y pobres, entre patrones e inquilinos, después llamados obreros", relación "que sigue teniendo una imagen premoderna, lejana a la igualdad ciudadana, rural en su esencia, paternalista por una parte y despreciativa a la vez del pueblo y de profunda raigambre oligárquica" (57).

Los postulados de José Bengoa permiten entender, en parte, las relaciones que se generan en la novela de Atías entre el espacio rural (el fundo de Fernando Blanco, donde rige la explotación y el autoritarismo) y las formas asimétricas con que se relacionan los personajes citadinos.

Cabe destacar que entre los tres sectores sociales incorporados en $\mathrm{El}$ tiempo banal se producen vasos comunicantes que evidencian el hiato profundo existente entre las clases sociales. Esto se hace patente cuando Alberto comienza a hacerle clases de castellano a la hija de los aristócratas y para ello debe subir al barrio alto y al "corazón de la burguesía" (30), ámbito que lo hace sentir en un mundo extraño y distante. La posición crítica del 
narrador se evidencia al aludir a la ostentación característica de la clase alta en ascenso:
"Alberto comprendía que en esa muestra de estilos, en ese alarde un tanto versátil de profesionales que hacían continuas concesiones a los gustos de una clientela en pleno ascenso social, había una falta de teoría general, un desarraigo con el bello paisaje montañés que rodea esos barrios" (30).

El forzado contacto entre las clases sociales se hace patente cuando Fernando Blanco coincide con la poeta Cora en una celebración. En dicho evento, gestionado por Marianita -aristócrata que sirve "de agente relacionador entre los diversos núcleos literarios y las clases altas"- (66), Fernando mira a Cora despectivamente y emite un juicio donde el clasismo se evidencia en su versión más brutal: "La observó con el desdén que saben poner en sus miradas los aristócratas del país, en ese balance que hacen de las personas de un rango social inferior cuando les toca enfrentarlas" (68). Se revela aquí la fricción entre prácticas de clase. Mientras que la compartimentalización de la ciudad evidencia la profunda incomunicación entre los personajes que la habitan, la perspectiva clasista, en este caso, deviene en el elemento responsable de la desintegración. Como puede apreciarse, El Tiempo banal refleja la crisis generalizada que sufre Chile en la década del 50, siendo la incomunicación y la tensión entre las clases sociales solo una de sus aristas más visibles.

Es importante señalar que no son únicamente los escritores del 38 quienes reflexionan sobre las causas profundas de dicha crisis, sino también pensadores de otras disciplinas, cuyas propuestas entran en consonancia con el discurso de ideas desplegado en las novelas. Es el caso del libro En vez de la miseria, del economista Jorge Ahumada, del año 1958, donde se alude a la crisis generalizada que sufre Chile en esa década. Algunas causas son la inflación desenfrenada y la falta de oportunidades para los más necesitados. En un contexto más global, lo anterior es consecuencia, principalmente, de los enormes cambios producidos en el ámbito económico, social y cultural. Según Ahumada, a partir de la depresión mundial de los años 30, Chile no logró generar soluciones integrales que permitieran superar el conflicto existente. Las transformaciones producidas no estuvieron a la altura del problema, pues, a pesar de algunas importantes modificaciones destinadas a paliar la crisis del salitre, dichos cambios no fueron lo suficientemente expandidos en el orden social y económico. Lo anterior, unido a la disminución de la 
población rural (la que se redujo de 900.000 en 1940 a 25.000 en 1952) incide en que no se hayan podido disolver ciertos resabios feudales, tanto en la esfera de lo jurídico como en el sistema educacional. Ello se evidencia, por ejemplo, en que, al igual que en los antiguos feudos, los "aristócratas crean que la ley no rige para ellos" y por otro lado "el pueblo no entienda que la ley tiene por sentido la protección de los derechos" (25). Para Ahumada, la causa principal de la crisis es la enorme diferencia en la distribución de los ingresos y la incapacidad para solucionar dicho problema:

"El ingreso de las clases ricas tomadas en conjunto y por persona es igual a cinco veces y media el ingreso que gozan los obreros. Los ricos son apenas el 5 por ciento de la población del país, pero gozan en conjunto de más de un tercio de toda la producción nacional. Por otra parte, las 740 mil familias de los obreros chilenos, que forman el $59 \%$ de la población gozan de apenas un quinto del total de la producción" (75).

Es denigrante, según plantea Ahumada, “el espectáculo de la sórdida pobreza de los más, en contraste con la ostentación orgullosa de los menos" (13). En un contexto de sociabilidad de ese tipo los ricos tratan despreciativamente a los pobres y estos responden con un evidente odio social.

El contexto social al que se refiere Ahumada dialoga con el verosímil de El tiempo banal. Ayuda a comprender, además, las características del mundo representado, de los personajes y de la clase social que encarnan. $\mathrm{Al}$ mismo tiempo, debe señalarse que la ficción narrativa despliega el tema de la adquisición de conciencia como elemento articulador de los personajes. En el caso del aristócrata Fernando Blanco, dicha crisis remite a los momentos en que su contador de la Bolsa le informa -en su fundo del sur-que ha sido estafado por un socio americano que realizó fallidas especulaciones en los "bancos yanquis" (210). La quiebra financiara lo dejará a él como responsable ante los corredores de cambio, a quien deberá restituir la suma de 200.000 dólares, cifra que no podrá cancelar. Sin embargo, la gravedad de la situación no se compadece con el nuevo estado de ánimo del afectado: “¿Por qué entonces esa suerte de placer, de goce insólito que comenzó a adueñarse de él? Todo estaba en juego, Eugenia, el fundo, la parentela: a todos alcanzaría ese golpe formidable" (212). Lo irreversible de la derrota financiera lo hará consciente de que sus relaciones familiares, especialmente con su esposa, han sido siempre vacías y banales. 
Por otro lado, la ruina económica de Fernando Blanco corre en paralelo a la toma de conciencia de las circunstancias miserables en que viven sus trabajadores en el fundo. Al mismo tiempo se informa que el movimiento campesino se está irradiando por todos los campos del sur, demandando justicia, mejores sueldos y mayor dignidad. El narrador precisa que quien realiza la arenga ante el patrón "hacía recuerdos también del año 1938, cuando el Frente Popular organizó sindicatos en la región" (290). Fernando Blanco se sensibiliza por vez primera a las demandas del otro: "Sucede que esos campesinos están aburridos de esperar" (293) Comprenderá la magnitud de los reclamos de sus inquilinos y entenderá que para ellos él siempre ha sido un perfecto extraño.

En el caso de Alberto, personaje prototipo de la clase media, la crisis de identidad que irá sufriendo a lo largo de la novela se logra definir mejor en el viaje que emprende al fundo de los Blanco, con el fin de continuar haciéndole clases a la hija de estos:

"Su crisis era más honda ¿Cómo explicarla? Representaba más que una contradicción; el proceso histórico se interrumpía en él. El proletariado planteaba sus luchas en otro terreno, eran fuerzas históricas, pugnaban contra algo evidentemente concreto, la enajenación del trabajo. Pero él no era un productor y en cierto sentido, tampoco era un explotado (...) el era un artista; su arte sería necesario"(158).

La sensación de no tener un proyecto social donde verse reflejado y el sentimiento de traición hacia sus antiguos ideales agudiza su estado de desajuste interior. Hablando de sí en tercera persona argumenta: "Helo ahí rozándose con aristócratas, divirtiéndose de algún modo con aristócratas. Abajo estaban los campesinos que había ayudado a organizar durante el Frente Popular; los campesinos que había amado el año 1938. No había avanzado una pulgada desde entonces" (294). La alusión al Frente Popular y la adscripción de Guillermo Atías a la generación del 38 se evidencian y ficcionalizan en estos párrafos de la novela. Es elocuente el autorrechazo del personaje por su falta de consistencia política y su precariedad existencial: "No tengo fuerzas para plantar un cambio en mi espíritu. Ya ha claudicado algo en mí. La acusación de reaccionario que se me hace a menudo, es justa. Pero no puedo ni siquiera desaparecer" (274).

En cuanto al cartero, personaje que encarna a la clase baja, su crisis y toma de conciencia posee dos frentes de expresión. El primero remite al ámbito 
afectivo y a la crisis matrimonial que sufre, pues su esposa Luisa lo dejará por irse con el Chano. Ni todo el amor y preocupación por ella logran compensar la sed de aventura que éste despierta en su esposa. Después de intentar por todos los medios revertir la situación, Luisa finalmente se va con su amante, y el cartero entenderá que debe buscar en la vida y en la sociedad valores de otra naturaleza. Es aquí donde la crisis que sufre encuentra el otro ámbito de acción y restitución de la dignidad: la adquisición de la conciencia social. El contexto donde lo anterior sucede es la huelga de carteros que se inicia en el país. Él, que hasta ese momento había vivido solo para su esposa, ahora comienza a involucrarse en los preparativos de la huelga: "El cartero ocupaba uno de los lugares principales, junto al presidente del comité. El movimiento gremial lo había ido comprometiendo insensiblemente; ahora era responsable de varios cargos en el comando de la huelga" (187). El dolor por la decisión de su esposa se confunde ahora con la conciencia lúcida de la situación que sufre el pueblo: "Los asalariados no luchamos por ser felices. La felicidad es una suerte; por lo que luchamos es para salir de las tinieblas, para saber para qué vivimos. Yo no sé para qué vivo" (237). Sin embargo, asumir su fracaso matrimonial le permitirá entregarse ahora a un proyecto común, a partir de la dignificación del rol que posee en la sociedad: "Yo soy un cartero -se decía- y este es mi trabajo (...) Era una resignación, pero al mismo tiempo, la búsqueda de un valor al que aferrarse: el trabajo. La vergüenza que roía su animo, cierta repugnancia por su propia existencia, le señalaron una salida (...) Toda esa historia de amor no era más que una miserable basura que era necesario arrojar al olvido" (305). Ahora está en condiciones de seguir adelante. Al concluir los siete días de huelga y al enfrentar las críticas al comando por no lograr los beneficios que se esperaban, demostrará una disposición nueva que revela una particular sabiduría social y política: "No hemos fracasado. Al contrario, hemos aprendido" (304).

Una vez que los personajes han adquirido conciencia de su lugar en la sociedad, la novela alcanza su momento final. El aristócrata Fernando Blanco, ya en plena bancarrota, termina dando declaraciones en una prefectura de carabineros. Frente a sus ojos el cartero espera para ser interrogado por su supuesta relación con el Chano, el amante de Luisa. Sin embargo, ambas derrotas devienen formas de liberación e implican una nueva forma de conexión con el otro. La novela se cierra cuando Fernando Blanco pide un fósforo al cartero "mirándolo por primera vez directamente" (309). El orden opresivo denunciado antes en La sangre y la esperanza ha encarnado ahora en una clase social representativa de dicho sistema. Sin embargo, a 
nivel del discurso de las ideas, queda demostrado que nadie tiene asegurado sus privilegios y que sí es posible la renovación de las estructuras sociales y de las relaciones humanas.

\section{CONCLUSIONES PRELIMINARES}

Las tres novelas estudiadas posibilitan visualizar un sentido de ideología que involucra ideas y creencias portadoras del imaginario de su época, las que simbolizan las condiciones y experiencias de vida de un grupo socialmente significativo. Aquí, el concepto de ideología se hermana al de cosmovisión (Eagleton 52), lo que permite, en este caso, develar una concepción de la literatura que la entiende como un posicionamiento crítico ante el entorno de producción de la misma. La obra literaria del 38 aspira a la construcción de un mundo cargado de sentido y a un productivo diálogo con la realidad social y concreta ${ }^{8}$.

Las novelas de la generación del 38 revisadas permiten develar una imagen hermenéutica de un mundo representado signado por el cronotopo de la exclusión. La primera modalidad de exclusión, visualizable en Angurrientos de Juan Godoy, remite a un ámbito social donde la miseria tiende a reproducir los mecanismos destructivos que la perpetúan. Exclusión y segregación se concentran en un territorio cercado donde no parece haber salida para los que experimentan dichas formas de opresión. En cambio, en la segunda modalidad de exclusión revisada, a partir de La sangre y la esperanza, de Nicomedes Guzmán, el lugar representado, es decir, el conventillo, se ofrece como un lugar privilegiado para una praxis política que permita liberar el aislamiento y gestionar el cambio revolucionario. Por último, la tercera modalidad de exclusión no se concentra ya únicamente en mostrar la marginalidad, sino en las diversas facetas en que se expresa la erosionada trama social. Dentro de esta compleja variedad de perspectivas, el mal del clasismo se constituye en una de las raíces del desencuentro y la injusticia social.

Las tres modalidades de exclusión revisadas permiten acceder a diversas formas en que el arte narrativo de la generación del 38 procesa el discurso de

8 Puesto que "un texto narrativo cobra sentido solo en la media en que el universo diegético entre en relación significante con el mundo real. Así la creación de un mundo constituye un contrato de inteligibilidad con el lector" (Pimentel 9). 
las ideas de su tiempo. El cronotopo de la exclusión se comporta entonces como un ideologema que revela la crisis del discurso integrador nacionalista y la operatividad de una escritura al servicio de los imperativos de transformación social, vigentes en la época.

\section{BIBLIOGRAFÍA}

Ahumada, Jorge. En vez de la miseria. 1958. Santiago: Editorial del Pacífico, 1960.

Alegría, Fernando. Fronteras del realismo. Literatura chilena del siglo XX. Santiago: ZigZag, 1962.

Allende, Salvador. "La realidad médico-social chilena". Rumbo: Órgano oficial del Partido Socialista, No 9, 1940.

Anderson, Benedict. Comunidades imaginadas, Reflexiones sobre el origen y la difusión del nacionalismo. México: F.C.E., 1993.

Anguita, Eduardo. "Pájaros de la memoria". Plan N.92, Santiago, marzo, 1973.

Atías, Guillermo. Tiempo banal. Santiago: Nascimento, 1955.

"La literatura como lujo". La generación del 50 en Chile. 1991 (Editor: Eduardo Godoy). Curicó: Editorial La Noria, 1994.

Bajtin, Mijail. Problemas literarios y estéticos. La Habana: Editorial Arte y Literatura, 1986.

Bengoa, José. La comunidad perdida. Santiago: Ediciones Sur, 1996.

Cornejo Polar, Antonio. Sobre Literatura y Crítica Latinoamericanas. Caracas: Ediciones de la Facultad de Humanidades y Educación. Universidad Central de Venezuela, 1982.

De la Fuente, José. Narativa de vanguardia, identidad y conflicto social. Santiago: Ediciones Universidad Católica Silva Henríquez, 2007.

Eagleton, Ferry. Ideología. Buenos Aires: Paidós, 1997.

Franz, Carlos. La muralla enterrada. Bogota: Planeta, 2001.

Godoy, Juan. Angurrientos. 1940. Santiago: Ed. Lom, 1996.

"El Angurrientismo", en Aurora de Chile, Alianza de intelectuales, sin fecha, Referencias críticas de DIBAM.

Gorki, Máximo. Pensamientos sobre la literatura y el arte. Moscú: Editorial Progreso, 1981.

Guerra Cunningham, Lucía. "El conventillo en Los hombres oscuros, de Nicomedes Guzmán”. Anales de Literatura Chilena, 1/1, 2000

Guzmán, Nicomedes. La sangre y la esperanza. 1943. Santiago: Ediciones Olimpo, 2003. "Literatura y vida". Las Últimas Noticias, 3 de junio de 1961.

Hidalgo, Rodrigo y Rafael Sánchez: "Del conventillo a la vivienda: casas soñadas, poblaciones odiadas". Historia de la vida privada en Chile. Tomo 3, Santiago: Ed. Taurus, 2007. 
Jobet, Julio César. "Visión de Chile postrado". Rumbo: Órgano oficial del Partido Socialista, $n^{\circ} 9,1940$.

Lefebvre, Henri. La revolución urbana. Madrid: Alianza Editorial, 1972.

Matta, Roberto. Revista Araucaria, nº 1, 1978.

Montes, Hugo. Historia de la Literatura Chilena. Santiago: Zig-Zag, 1973.

Ortiz Letelier, Fernando. El movimiento obrero en Chile (1891-1919). Santiago: Ed. Lom, 2005.

Oyarzún, Luis. “Crónica de una generación”, Atenea, Año XXXV, Tomo CXXXI, № 380381.

Pimentel, Luz María. El espacio en la ficción, ficciones espaciales: La representación. México: Ed. Siglo XXI, 2001.

Pinochet, Tancredo. La obra. Santiago: Imprenta La Ilustración, 1911.

Plath, Oreste. El Santiago que se fue. Santiago: Grijalbo, 1997.

Promis, José. La novela chilena del último siglo. Santiago: Editorial La Noria, 1993.

Romero, José Luis. Latinoamérica, las ciudades y las ideas. México: Siglo XXI.

Salazar, Gabriel. "Construcción de Estado en Chile: la historia reversa de la legitimidad". Proposiciones 24, 1994.

Sánchez Latorre, Luis. Diálogo entre Profesores de Literatura, ensayistas y críticos, en $L a$ generación del 50. 1991. Curicó: Editoral La Noria, 1994.

Sarrochi, Augusto. Diálogo entre Profesores de Literatura, ensayistas y críticos, en La generación del 50. 1991. Curicó: Editoral La Noria, 1994.

Segre, Césare. Principios de análisis del texto literario. Barcelona: Ed. Crítica, 1985.

Silva Castro, Raúl. Panorama literario de Chile. Santiago: Ed. Universitaria, 1961.

Subercaseux, Bernardo. Chile revisitado (Sonia Montecino, compiladora), Santiago: Cuadernos Bicentenario, 2003.

Historia de las ideas y de la cultura en Chile. Tomo IV, Santiago: Editorial Universitaria, 2007.

Genealogía de la vanguardia en Chile. Santiago, Ediciones Facultad de Filosofía y Humanidades, Universidad de Chile (sin fecha de edición).

Teitelboim, Volodia. "La generación del 38 en busca de la realidad chilena", Atenea, año XXXV / Tomo CXXXI, No 380-381.

“Sobre la generación del 38". Pluma y Pincel, n 170, 1994.

Uriarte, Fernando. "La novela proletaria en Chile". Mapocho 4, 1965.

Vicuña Mackena, Benjamín. La transformación de Santiago. Santiago, Chile, 1872.

Zhdánov, Andrei. "El realismo socialista". Estética y marxismo, Tomo II (Antologador: Adolfo Sánchez Vásquez). México: Ediciones Era, 1970. 